\title{
5-Azacitidine/Gemcitabine Regimen
}

National Cancer Institute

\section{Source}

National Cancer Institute. 5-Azacitidine/Gemcitabine Regimen. NCI Thesaurus. Code C161964.

A chemotherapy regimen consisting of 5-azacitidine and gemcitabine that may be used in the treatment of pancreatic cancer. 